\title{
On Professional Prerogatives
}

\author{
by Robert C. Post*
}

Derek Bok seems to have struck a nerve. The accusation that lawyers are parasitic, concerned with issues of distribution rather than production, resonates with the current national mood, with its resurgent glorification of the entrepreneur and its abandonment of the social programs of recent decades.

The accusation prompts Robert Kagan and Robert Rosen to question whether an imaginary "Czar of Personnel" would be justified in assigning our best and brightest young people to careers in prestigious corporate law firms. They conclude that such assignments would be mistaken, since large law firm practice is of "declining social significance." I Lawyers engaged in such firm practice no longer "serve as molders of corporate and public policy," 2 but instead have retreated to a narrow and technical legal craftsmanship.

Thus, whereas Bok complains that lawyers are not productive, that they do not make "the pie grow larger" but only "decide how to carve it up,"3 Kagan and Rosen issue a different indictment, that lawyers are failing to provide enough ethical and social guidance to corporate entities. If Bok's accusation is imbued with the diminished expectations and deflated realism of the 1980s, Kagan and Rosen's retains the high aspirations and moral promise of the 1960s. They remind us that there is more to life than efficiency.

Their article thus raises issues quite different than those implied by Bok's dour accusation. To evaluate whether lawyers are really pulling their social weight, we would have to engage in a rather hard-nosed assessment of the value we place on our pres-

* Acting Professor of Law, School of Law, University of California, Berkeley. A.B., 1969, Harvard; J.D., 1977, Yale Law School; Ph.D., 1980, Harvard University.

1. Kagan \& Rosen, On the Social Significance of Large Law Firm Practice, 37 Stan. L. REv. 399, 434 (1985).

2. Id. at 435 .

3. Bok, Annual Report to the Board of Overseers, Harvard Univsersity, quoted in N.Y. Times, Apr. 22, 1983, at Al, col. 1. 
ent legal system, with its emphasis on judicial dispute settlement, its focus on legal entitlements and duties, and its utilization of the adversary system. But Kagan and Rosen appear uninterested in this kind of an evaluation. ${ }^{4}$ They care about whether lawyers can make a better pie, not simply a bigger one. Their focus is thus on the extent to which lawyers can and should transcend their role as mere "expert suppliers of legal information and as performers of complex and specifically legal tasks,"5 and assume instead the socially more important role of "independent counselors."6 The question, however, is whether this is indeed a better recipe for our social condition.

The question arises because Kagan and Rosen define the role of "independent counselor" by reference to two special variables, autonomy and influence. To those familiar with the sociological literature on professionals, these variables have a familiar ring. Professionals characteristically provide the public with services which consist of the application of a specialized and expert knowledge. Since members of the public do not share this knowledge, they can evaluate its use only with great difficulty. For this reason, professionals usually require and receive a fair degree of "autonomy" in the exercise of their professional expertise. ${ }^{7}$ But professionals, including lawyers, face a tension between service and autonomy. The concept of autonomy implies that professional performance can only be evaluated by those with the expert knowledge prerequisite to informed judgment, which is to say by the profession itself. ${ }^{8}$ The concept of service, on the other hand, implies that the measure of a professional's

4. Kagan and Rosen's indictment is instead carried along by analogies between lawyers and "the architects hired by the corporation to design a new . . . factory" who decide "how to achieve specific ends already decided upon by corporate management." Kagan \& Rosen, supra note 1, at 413-14. Even if this were an accurate description of an architect's role, it would not follow that the profession of architecture is unproductive in Bok's sense. The social utility of architecture would depend upon the social service provided by the profession, regardless of whether this service involved only the accomplishment of specific ends dictated by others.

5. Id. at 440 .

6. Id. at 426 .

7. See M. Bayles, Professional Ethics 7-13 (1981); Scott, Professionals in Bureaucracies: Areas of Conflict, in Professionalization 265 (H.M. Vollmer \& D.L. Mills eds. 1966).

8. See Moore, The Profissions: Roles and Rules 87-106 (1970); Rueschemeyer, Professional Autonomy and the Social Control of Expertise, in THE Sociology OF THE ProfessIons 38 (R. Dingwall \& P. Lewis eds. 1983). 
performance should be the satisfaction of client needs. ${ }^{9}$ The ultimate importance of this service to the public is one measure of a profession's "influence."

The most intriguing aspect of Kagan and Rosen's paper is that they want to liberate the concepts of autonomy and influence from this traditional and restricted context, and to fill them with new and special meaning. They are quite clear that by lawyer autonomy they do not mean the ability to exercise the independent judgment necessary for the practice of a technical craft. They mean instead a lawyer's ability to transcend issues of merely "legal" consequence and to offer instead "autonomous evaluation of social consequences, political wisdom, or good business practices." 10 For Kagan and Rosen, lawyer autonomy lies in the freedom to give advice based upon "standards rooted in the law, public policy, and common conceptions of fair dealing." 11

Kagan and Rosen are somewhat less clear in their definition of "influence." At times they speak as though lawyers have influence if their services are important to a client and involve "fateful" rather than "peripheral" matters. ${ }^{12}$ At other times they speak of lawyers having influence if they "have the ear" of their clients, if their advice is actually followed. ${ }^{13}$ Both these senses of "influence" are compatible with the traditional image of the lawyer as a professional with a limited and technical legal expertise. Sometimes this expertise is important to the client, ${ }^{14}$ and sometimes it is not. It depends upon a variety of factors, including the relevance of the law to the client. If legal expertise is important to a corporate client, one can expect that it will attend to the advice of its lawyer.

To determine if lawyers have these kinds of "influence," one

9. See M. Larson, The Rise of Professionalism: A Judicial Analysis x-xii (1977); D. Rosenthal, Lawyer and Client: Who's in Charge? 7-28 (1974); Jones v. Barnes, 103 S. Ct. 3308 (1983).

10. Kagan \& Rosen, supra note 1 , at $436-37$.

11. Id. at 420 . I do not mean to draw this distinction too sharply. It might reasonably be argued, for example, that the provision of even strictly "legal" advice requires an understanding of general social, political, or business practices. Kagan and Rosen appear to define autonomy, however, in terms of the ability to draw upon such general understandings in ways not specifically necessary for the provision of legal services.

12. Id. at 416 .

13. Id. at 406.

14. For example, when lawyers "are called upon to advise corporations with wholly unfamiliar territory, such as their first encounter with a 'hostile takeover,' beginning trade with the Peoples' Republic of China, or attempting to protect property interests in post-revolutionary Iran." Id. at 425. 
would have to closely examine the relationship between corporations and their legal environment. But this is not what Kagan and Rosen have in mind, and so I think that they ultimately mean something quite different by the concept of "influence." They mean that lawyers have influence if they affect a "client's goals and policies." 15 For Kagan and Rosen, a lawyer is "influential" if he does not merely take orders from the corporate managers he advises, but rather helps to develop these very policies. ${ }^{16}$ Note that in this sense the concept of "influence" transcends the traditional image of the legal professional, in which, to quote from the ABA's new Model Rules of Professional Conduct, lawyers are required to "abide by a client's decisions concerning the objectives of representation." 17

Kagan and Rosen thus propose that lawyers become independent counselors who offer advice that is not restricted to issues of legal expertise, but ranges instead over a large spectrum of business, social, and ethical judgment, and who do not merely take orders from their clients, but rather attempt to use their judgment as a basis for altering their clients' objectives. The proposal is interesting and radical because it so deeply transforms our usual notion of a professional. As Kagan and Rosen note, "In one sense . . . the image of the autonomous and influential attorney is not a 'professional' one." 18

In another sense, however, Kagan and Rosen make the important claim that the definition of a professional role is historically contingent, ${ }^{19}$ and that it is therefore not self-defining. Their complaint is that in recent years lawyers have adopted an unduly limited and technical definition of their role. ${ }^{20}$ This definition is not necessitated by the market for legal services, since lawyers hold a monopoly and can impose on their clients their own definition of proper professional service, and since "professions traditionally have justified their privileged position by the claim that professional standards, not merely client demand, govern their

15. Id. at $419-20$.

16. Id.

17. Model Rules of Professional Conduct Rule 1.2(a) (1983).

18. Kagan \& Rosen, supra note 1 , at 430 .

19. For illuminating examples of previous professional definitions of the lawyer's role, see Gordon, Legal Thought and Legal Practice in the Age of American Enterprise, in Professions and Professional Ideologies in America 70 (G. Geison ed. 1983); R. FerguSon, Law and LetTers in American Culture (1984).

20. Kagan \& Rosen, supra note 1 , at 422. 
work."21 What is needed, Kagan and Rosen imply, are new professional standards that incorporate the values of autonomy and influence.

This implication is at the core of Kagan and Rosen's paper. The difficult and important question that it raises is whether the values of autonomy and influence, as defined by Kagan and Rosen, can or should serve as the basis for a professional ethos. Recall that the very raison d'etre of a profession is its claim to special expertise. Lawyers claim to know the law, and it is upon this claim that their status as professionals rests. For Kagan and Rosen's position to be accepted, it must be established that lawyers can claim a similar expertise with respect to matters of business, social, and ethical judgment. ${ }^{22}$ Kagan and Rosen's position appears to be that lawyers should be encouraged to express such judgments in their professional capacity, and that clients should attend to such judgments as they would to the advice of a professional.

I have two reservations about this position. First, I doubt whether such judgments can be made the subject of professional expertise. Certainly "general principles of equity, fair dealing, and public policy" are not susceptible to privileged "professional" insight. They pose instead general issues of right and wrong, of tact and judgment, that are open to the perception of professional and nonprofessional alike. This does not mean that they are issues without answers, only that there is no particular reason to trust an expert's answer.

Second, I doubt whether it would be desirable to commit such issues to expert resolution. The twentieth century has witnessed a continual tug-of-war between the prerogatives of expertise and the principles of democracy. ${ }^{23}$ The expert claims to have special knowledge of public policy; the democrat maintains that valueladen issues pose political questions that must be decided by the people themselves. There is much to be said on both sides, but the point I wish to emphasize is that the professionalization of

21. Id. at 440 .

22. Kagan and Rosen develop their insight in the area of corporate practice where these are the relevant variables to describe influence and autonomy. In other contexts, other variables may be appropriate. For example, if lawyers were to exercise autonomy and influence in the area of divorce law, it might be on the basis of a claimed expertise in family psychology.

23. See, e.g., E. Purcell, The Crisis of Democratic Theory: Scientific NaturalisM aNd the Problem of VAlue 95-114 (1973). 
knowledge has its costs. Inquiry that becomes the subject of expert prerogative tends to become depoliticized, which means that it slips from the arena of public discussion, and its roots in ethics and public policy fade from public awareness. This may not be a good thing. I, for one, would think it very unfortunate if lawyers were to be perceived as "experts" in matters involving business, social, or ethical judgments, so that members of the public would feel incompetent to challenge such judgments or to perceive and debate the values that underlie them.

For these reasons I do not agree that lawyers should strive for professional standards that incorporate the values of autonomy and influence, as Kagan and Rosen have defined them. This is not to say, however, that professional standards should discourage lawyers from exercising autonomy and influence, so long as this is done without the pretense of professional authority. ${ }^{24}$ As Kagan and Rosen suggest, it would be a great loss if those who assume the prerogatives of the profession must simultaneously lose their human prerogative to exercise these important values. That would be a poor recipe for a desirable social life. And in this context, Kagan and Rosen perform a valuable service indeed by detailing the many ways in which the social conditions of legal practice and the currents of professional culture tend toward this unfortunate result.

24. The new ABA rules permit the exercise of autonomy: "In rendering advice, a lawyer may refer not only to law but to other considerations such as moral, economic, social and political factors, that may be relevant to a client's situation." MODEL RuLes OF Professional Conduct Rule 2.1 (1983). Although the rules presuppose a situation in which clients set objectives and lawyers implement them, they do not directly forbid the exercise of influence. See id. at Rule 1.2 and Comment (1); Rule 1.14 and comment (1). There is always a question, however, whether a trusting client can distinguish advice based upon professional expertise and advice based upon a lawyer's exercise of autonomy and desire for influence. 